\title{
Simulation and experimental approach for shot velocity evaluation in ultrasonic shot peening
}

\author{
Jawad Badreddine ${ }^{1, a}$, Emmanuelle Rouhaud ${ }^{1}$, Matthieu Micoulaut ${ }^{2}$, \\ Delphine Retraint ${ }^{1}$, Sébastien Remy ${ }^{1}$, Manuel François ${ }^{1}$, Pascal Viot ${ }^{2}$, \\ GaËlle Doubre-Baboeuf ${ }^{3}$, Didier Le Saunier ${ }^{3}$ and Vincent Desfontaine ${ }^{4}$ \\ 1 Laboratoire des Systèmes Mécaniques et d'Ingénierie Simultanée (LASMIS), Université de Technologie de Troyes, \\ 12 rue Marie Curie, 10000 Troyes, France \\ 2 Laboratoire de Physique Théorique de la Matière Condensée (LPTMC), Université Pierre et Marie Curie, \\ 4 place Jussieu, 75252 Paris, France \\ 3 SNECMA Évry-Corbeil, route Henri Auguste Desbruères, BP 81, 91003 Évry, France \\ ${ }^{4}$ SONATS SAS, 2 rue de la Fonderie, BP 40538, 44475 Carquefou Cedex, France
}

Received 3 May 2011, Accepted 23 May 2011

\begin{abstract}
The process of ultrasonic shot peening has been studied from two aspects: (a) a 3D numerical model of shot motion in the peening chamber based on the theory of granular gases, (b) an experimental setup developed for measuring shot velocity distribution in the chamber and impact locations on the peened surface. The aim of such study is to propose an experimental method providing shot trajectories in order to validate the $3 \mathrm{D}$ model for the process parameter optimization, used for example in the aeronautic industry. The presented results illustrate the value of the model in the understanding and mastering of the process, as well as its usefulness, on one hand for the design of peening chambers, and on the other hand for a better definition of numerical models that help to predict residual stresses generated in the peened material.
\end{abstract}

Key words: Ultrasonic shot peening / experiment / simulation / shot velocity / coverage

Résumé - Simulation et approche expérimentale pour l'évaluation des vitesses de billes pour le grenaillage ultrasons. Nous avons étudié le procédé de grenaillage ultrasons sous deux aspects : (a) un modèle numérique 3D de la dynamique des billes dans l'enceinte de traitement basé sur la théorie des gaz granulaires, (b) un dispositif expérimental développé pour mesurer la distribution des vitesses des billes dans l'enceinte et au niveau de la surface traitée. L'intérêt d'une telle étude est de proposer une méthode expérimentale qui donne accès aux trajectoires des billes et de valider le modèle numérique pour optimiser les paramètres de ce procédé, utilisé par exemple en aéronautique. Les résultats présentés dans ce manuscrit illustrent l'intérêt du modèle dans la compréhension et la maîtrise du procédé, ainsi que son utilité, d'une part pour la conception des enceintes de grenaillage, et d'autre part pour une meilleure formulation de modèles numériques servant à la prédiction des contraintes résiduelles générées dans le matériau grenaillé.

Mots clés : Grenaillage ultrason / expérience / simulation / vitesse de billes / recouvrement

\section{Introduction}

Ultrasonic shot peening is a mechanical surface treatment process that consists in throwing spherical shot onto the surfaces of a component to be treated. Shot is placed and contained in a treatment chamber. A generator produces the vibration of a "sonotrode", generally located in the bottom of the chamber, with an ultrasonic frequency which propels the shot towards the top with high

\footnotetext{
${ }^{a}$ Corresponding author: jawad.badreddine@gmail.com
}

velocities. The multiple impacts on the part induce compressive residual stresses in the material, thus enhancing its mechanical characteristics as well as its lifespan. These residual stresses highly depend on process parameters such as shot characteristics, shot velocities, impact angles and peening coverage [1-3].

Many numerical models for the prediction of these residual stresses can be found in the scientific literature, like finite element models [4-7] that give direct access to the induced residual stresses, or analytical [8] and 


\section{Nomenclature}

\begin{tabular}{|c|c|c|}
\hline Symbols & Definition & SI Unit \\
\hline$(X, Y, Z)$ & Global three dimensional orthonormal coordinate system & \\
\hline$A$ & Amplitude of vibration of the sonotrode & $\mu \mathrm{m}$ \\
\hline$B$ & Chamber width along $Y$ & $\mathrm{~mm}$ \\
\hline$C_{i}(V)$ & Normal restitution coefficient of $i$, for a normal impact velocity $V$ above threshold $V_{i}$ & \\
\hline$C_{i}^{0}$ & Normal restitution coefficient of $i$, for a normal impact velocity below threshold $V_{i}$ & \\
\hline $\mathrm{d} t$ & Time interval between two successive positions of a particle & $\mathrm{s}$ \\
\hline $\mathrm{d} x$ & Distance along $X$ separating two successive shot positions & $\mathrm{mm}$ \\
\hline $\mathrm{d} y$ & Distance along $Y$ separating two successive shot positions & $\mathrm{mm}$ \\
\hline $\mathrm{d} z$ & Distance along $Z$ separating two successive shot positions & $\mathrm{mm}$ \\
\hline $\mathrm{Fr}$ & Frequency of vibration of the sonotrode & $\mathrm{s}^{-1}$ \\
\hline$H$ & Chamber height along $Z$ & $\mathrm{~mm}$ \\
\hline$L$ & Chamber length along $X$ & $\mathrm{~mm}$ \\
\hline$V$ & Normal impact velocity of a shot & $\mathrm{m} . \mathrm{s}^{-1}$ \\
\hline$V_{i}^{0}$ & Velocity threshold of $i$, under which collisions are considered to be elastic & $\mathrm{m} . \mathrm{s}^{-1}$ \\
\hline$V_{\text {mean }}$ & Mean normal impact velocity during the peening time & $\mathrm{m} . \mathrm{s}^{-1}$ \\
\hline$V_{x}$ & Shot velocity along $X$ & $\mathrm{~m} \cdot \mathrm{s}^{-1}$ \\
\hline$V_{y}$ & Shot velocity along $Y$ & $\mathrm{~m} \cdot \mathrm{s}^{-1}$ \\
\hline$V_{z}$ & Shot velocity along $Z$ & $\mathrm{~m} \cdot \mathrm{s}^{-1}$ \\
\hline Greek symbols & Definition & SI Unit \\
\hline$\mu$ & Tangential restitution coefficient & \\
\hline$\varnothing$ & Shot diameter & $\mathrm{mm}$ \\
\hline$\theta$ & Incidence impact angle & $\operatorname{deg}$ \\
\hline Subscript & Definition & SI Unit \\
\hline $\bar{i}$ & $\begin{array}{l}\text { Element on which is applied the normal restitution } \\
\text { coefficient; } i=[\mathrm{SHOT} \text {, WALL, TOP, BOT }]\end{array}$ & \\
\hline
\end{tabular}

semi-analytical models [9] that combine finite element calculations with analytical equations. These models require different input parameters. On one hand, there are process parameters that are known, like in our case the diameter and material of the shot. On the other hand, there are also physical parameters characterizing ultrasonic shot peening that can be out of reach experimentally or simply unknown. This corresponds for example to the particles velocities and angles of impact distribution, their mean values, as well as the spatial impact distribution on the sample surface, during the ultrasonic peening operation. The peening chamber seems to be some kind of "black box" in which the shot dynamics is not fully understood and mastered. This lack of understanding leads quite often to the creation of numerical models that are not well correlated with the peening process itself, and with what happens on the peened sample. By identifying this general need in the field of ultrasonic shot peening, a model was developed, upstream of the models presented above, which enables to go inside the peening chamber and to track the movement of shot during the peening process. This allows simulating thousands of inelastic impacts from which are extracted, for each one of them, the number and time of impact. The three dimensional coordinates of the place of impact are also saved, as well as the particles pre and post impact velocities.

From the experimental point of view, many methods exist for measuring the velocity of projectiles [10-13].
Some of these methods, like [12], use the phase shift between signals that corresponds to times of impacts, which are recorded by two microphones apart from each other. Such method could be used for conventional shot peening, where shot trajectories are commonly known. Furthermore, it is very difficult to apply it to ultrasonic shot peening, where shot trajectories appear to be random. This makes the measurement of shot velocities during peening very difficult, and explains partly the lack of available data. The developed experimental setup uses an optical measurement method that gives access to shot trajectories in the treatment chamber during the peening process.

\section{Shot dynamics model}

The model presented in this section simulates the dynamics of hard spheres placed in a rectangular chamber and propelled by a vibrating membrane onto a flat surface, as shown in Figure 1. These spheres represent the shot placed in the peening chamber and propelled by the sonotrode toward the sample to be peened. An EventDriven-Dynamics based algorithm [14] allows tracking the trajectory of the spheres. By simulating thousands of impacts onto the treated part, statistical studies are performed to determine the impact distribution and frequency, as well as the distributions of impact velocities and angles. 


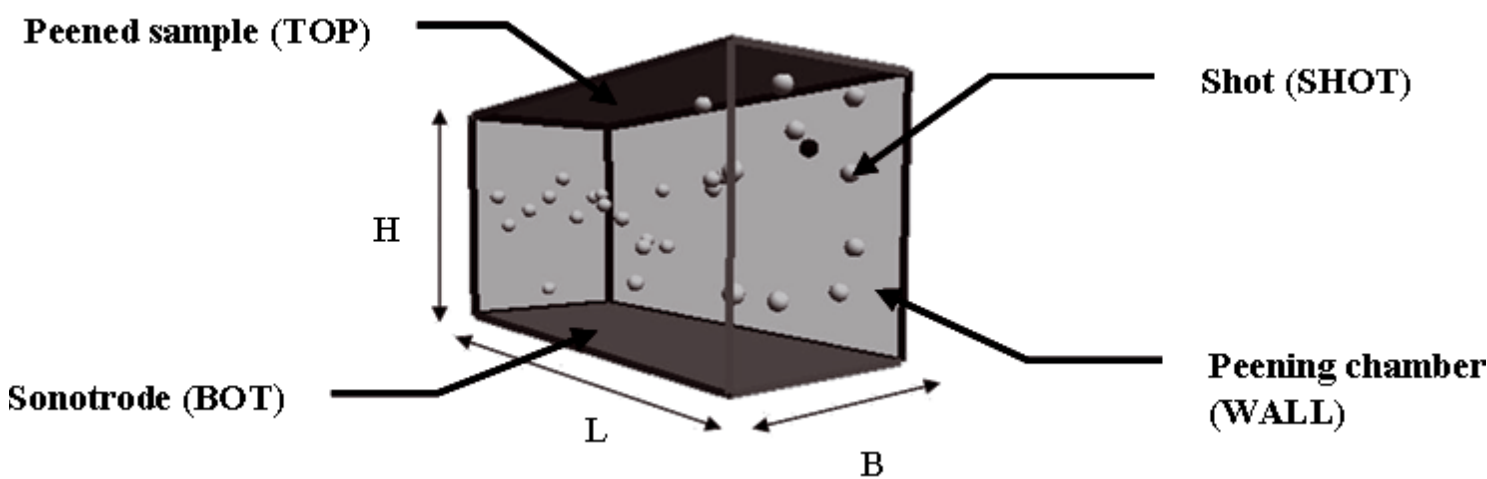

Fig. 1. Schematic illustration of the ultrasonic shot peening model for a rectangular chamber.

The model detects "shot-shot" and "shot-wall" impacts and takes into account the energy dissipation during the impacts through normal $\left(\mathrm{C}_{\mathrm{SHOT}}^{0}, \mathrm{C}_{\mathrm{WALL}}^{0}, \mathrm{C}_{\mathrm{BOT}}^{0}\right.$, $\left.\mathrm{C}_{\mathrm{TOP}}^{0}\right)$ and tangential $(\mu)$ restitution coefficients. The tangential coefficient is considered to be constant with a value of $5 / 7[15,16]$. The normal coefficients $\left(C_{\mathrm{i}}^{0}, i=\right.$ $\{\mathrm{SHOT}$, WALL, BOT, TOP $\}$ ), however, follow the power law given below; according to phenomenological models [16] and experiments [17]:

$$
C_{i}(V)=\left\{\begin{array}{l}
C_{i}^{0} \quad \text { if } \quad V<V_{i}^{0} \\
C_{i}^{0}\left(V / V_{i}^{0}\right)^{-1 / 4} \text { if } \quad V>V_{i}^{0}
\end{array}\right.
$$

In Equation (1), $V$ corresponds to the shot velocity, whereas $V_{i}^{0}$ is a velocity threshold under which the normal restitution coefficient is constant and equals to $C_{i}^{0}$.

Ultrasonic shot peening is believed to produce random shot trajectories during the peening process. Surface coverage and stress distribution can thus be supposed homogeneous. In this section, the possibilities offered by the model are illustrated with the study of the effect of the shot quantity on the normal impact velocity and angle distributions. Three amounts of shot will be tested: $5 \mathrm{~g}$ (45 particles), $10 \mathrm{~g}$ (90 particles) and $20 \mathrm{~g}$ (181 particles). A parallelepipedic peening chamber made of aluminum and 100 Cr6 steel spherical shot is used in Section 2 calculations. Under the peening chamber, a titanium sonotrode is placed, and on top of the chamber aluminum sample. The restitution coefficients $[17,18]$, as well as the process parameters, chosen for running the calculations, are listed in Table 1 . The extracted data from each calculation correspond to a peening time of $30 \mathrm{~s}$. In terms of impact on the sample, this corresponds to $17434 ; 35088$ and 67812 impacts respectively for the $5 \mathrm{~g}, 10 \mathrm{~g}$ and $20 \mathrm{~g}$ amounts.

\subsection{Impact velocity distribution}

The normal impact velocity is the component of shot velocity, normal to the studied surface. In the present case, this velocity component corresponds to $V_{z}$, on which we will focus. It can be observed that the increase in shot
Table 1. Process and numerical parameters used for the study.

\begin{tabular}{ll}
\hline Process parameters & Value \\
\hline Length of the chamber & $L=85 \mathrm{~mm}$ \\
Width of the chamber & $B=36 \mathrm{~mm}$ \\
Height of the chamber & $H=45 \mathrm{~mm}$ \\
Diameter of the particle & $\varnothing=3 \mathrm{~mm}$ \\
Amplitude of vibration of the sonotrode & $A=50 \mu \mathrm{m}$ \\
Frequency of vibration of the sonotrode & $F r=20 \mathrm{kHz}$ \\
\hline Numerical parameters & Value \\
\hline SHOT-SHOT impacts & $C_{\text {SHOT }}=0.91$ \\
SHOT-BOT impacts & $C_{\text {BOT }}=0.91$ \\
SJOT-TOP impacts & $C_{\text {TOP }}=0.6$ \\
SHOT-WALL impacts & $C_{\text {WALL }}=0.6$ \\
\hline
\end{tabular}

quantity increases the interactions between particles, decreasing the mean normal impact velocity and the percentage of high velocity impacts.

The normal impact velocity distribution at the peened sample, for the three amounts of shot, is presented in Figure 2. This distribution corresponds to the percentage of impacts that belong to velocity intervals of $0.13 \mathrm{~m} . \mathrm{s}^{-1}$ each. These intervals are defined between 0 and $V_{\max }$, the maximum normal velocity registered.

As shown in Figure 2, with $5 \mathrm{~g}$ of shot, $47 \%$ of the impacts on the sample have a normal velocity higher than $4 \mathrm{~m} . \mathrm{s}^{-1}$, whereas with $20 \mathrm{~g}$ of shot, only $10 \%$ of the impacts are concerned. With $20 \mathrm{~g}$ of shot, $57 \%$ of the impacts have low velocities $\left(V_{z}<1 \mathrm{~m} . \mathrm{s}^{-1}\right)$, against $16 \%$ with $5 \mathrm{~g}$. We also find this evolution for the mean normal velocity which goes from $3 \mathrm{~m} . \mathrm{s}^{-1}$ to $1.3 \mathrm{~m} . \mathrm{s}^{-1}$ when using respectively 45 and 181 particles.

\subsection{Impact angle distribution}

If we look now at the angles of impact, we notice that the denser the system (high amount of shot), the lower the quantity of normal impacts. This can be directly seen in the impact angle distribution (Fig. 3), which is the percentage of impacts corresponding to angle intervals defined between 0 and 90 degrees. For instance, a perfect normal impact on the sample will have an impact angle of 0 . 


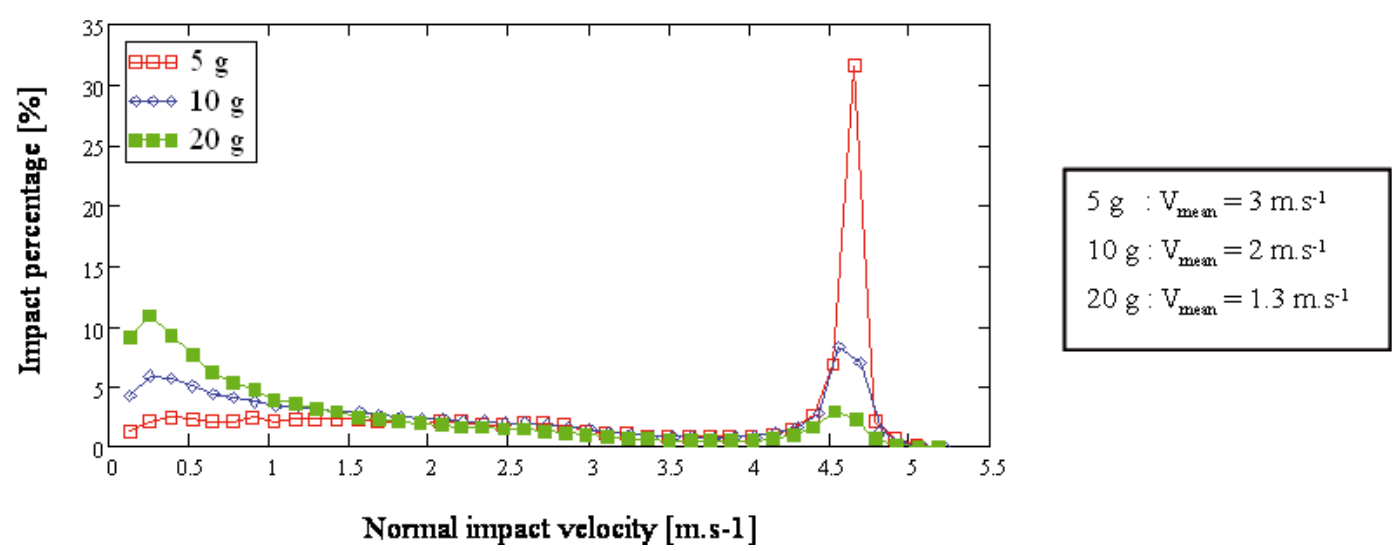

Fig. 2. Normal impact velocity distribution at the peened sample, for three quantities of shot: $(\square \square \square) 5 \mathrm{~g}=45 \mathrm{shot},(\diamond \diamond \diamond)$ $10 \mathrm{~g}=90$ shot, $(\square+\square) 20 \mathrm{~g}=181$ shot.

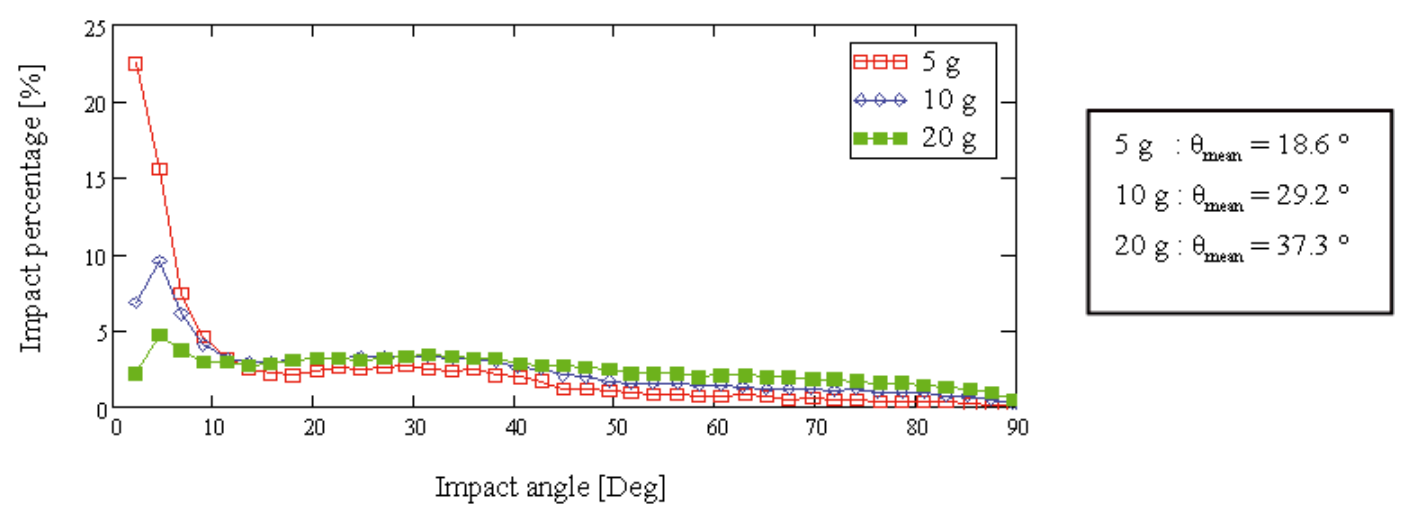

Fig. 3. Impact angle distribution at the peened sample, for three quantities of shot: $(\square \square \square) 5 \mathrm{~g}=45 \mathrm{shot},(\diamond \diamond \diamond) 10 \mathrm{~g}=$ 90 shot, (口ם) $20 \mathrm{~g}=181$ shot.

For a diluted system ( $5 \mathrm{~g}$ of shot), more than $50 \%$ of the impacts have an incidence angle lower than $10^{\circ}$, while it is $17 \%$ for a dense system ( $20 \mathrm{~g}$ of shot). The incidence angle is the angle made by the velocity vector and the normal vector of the peened surface. Similarly with $5 \mathrm{~g}$ of shot, $6.5 \%$ of the impacts have a high incidence angle (greater than $60^{\circ}$ ), while it is $22.3 \%$ with $20 \mathrm{~g}$. These results seem to indicate a tight correlation between the normal velocity and angle of impact of a shot.

\subsection{Correlation between impact velocity and angle}

To further clarify this point, we plotted on the same graph and for the same amount of shot the normal impact velocity distribution for: impacts with an incidence angle lower than $10^{\circ}$, higher than $60^{\circ}$ and the complete distribution.

Figures 4 and 5 show, clearly, the correlation between normal velocity and angle of impact for respectively $10 \mathrm{~g}$ and $20 \mathrm{~g}$ of shot. The same conclusion can be drawn from both cases. The large majority of the normal impacts (incidence angle lower than $10^{\circ}$ ) has a high normal velocity (here $V_{z}>4 \mathrm{~m} . \mathrm{s}^{-1}$ ), while the quasi-tangential impacts (incidence angle higher than $60^{\circ}$ ) have low normal impact velocities (here $V_{z}<1 \mathrm{~m} . \mathrm{s}^{-1}$ ). This can be explained by the existence of two families of shot in the chamber, during the treatment. The first family has trajectories corresponding to direct trajectories between the sonotrode and the sample, without being deflected. This shot possesses high normal velocities and very low angles of impact. Whereas the second family of shot corresponds to the shot deflected from their initial trajectories, on their way from the sonotrode to the sample. Due to multiple impacts with the chamber walls or with other shot, these particles usually hit the sample with low velocities and high incidence angles. The denser the system, the smaller is the probability for a shot to make a direct trajectory between the sonotrode and the sample.

\section{Experiment}

The experimental setup developed allows observing shot trajectories in the chamber and the sample coverage, using an optical method. Using the captured shot trajectories, with two cameras placed at $90^{\circ}$ from each other, it is possible to deduce the $3 \mathrm{D}$ coordinates $(X, Y$, $Z)$ of the shot, their velocity $\left(V_{x}, V_{y}, V_{z}\right)$ before and after an impact (Fig. 6a), as well as the incidence angles $\theta$ of the shot on the peened sample. 


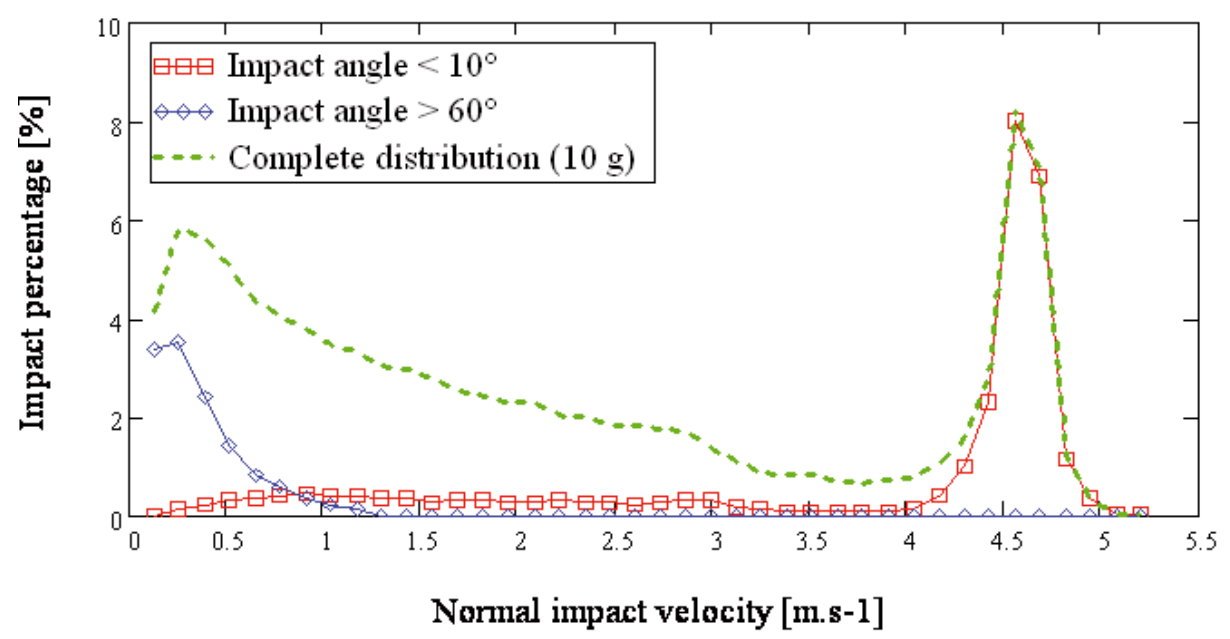

Fig. 4. Correlation between normal impact velocity distribution and the impact angle of a shot, for $10 \mathrm{~g}$ of shot. ( $\circ \circ \circ)$ Distribution for impact angles lower than $10^{\circ},(\diamond \diamond)$ distribution for impact angles higher than $60^{\circ},(---)$ complete normal impact velocity distribution for $10 \mathrm{~g}$ of shot.

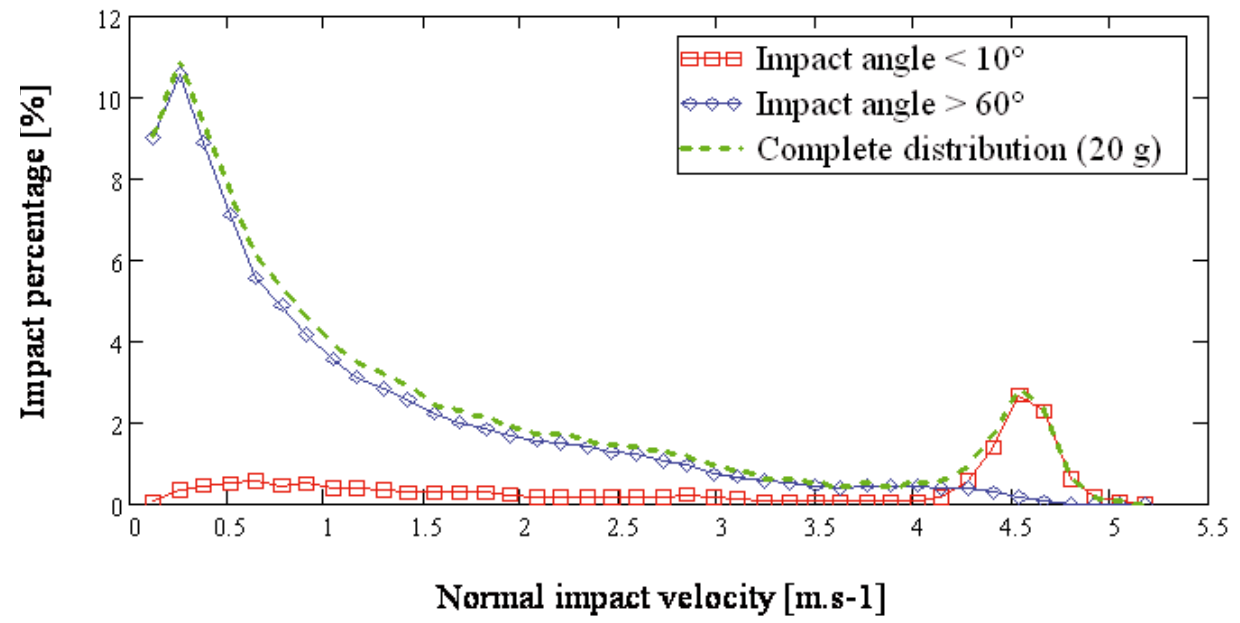

Fig. 5. Correlation between normal impact velocity distribution and the impact angle of a shot, for $20 \mathrm{~g}$ of shot. ( $\square \square \square$ ) Distribution for impact angles lower than $10^{\circ},(\diamond \diamond \diamond)$ distribution for impact angles higher than $60,(---)$ complete normal impact velocity distribution for $20 \mathrm{~g}$ of shot.

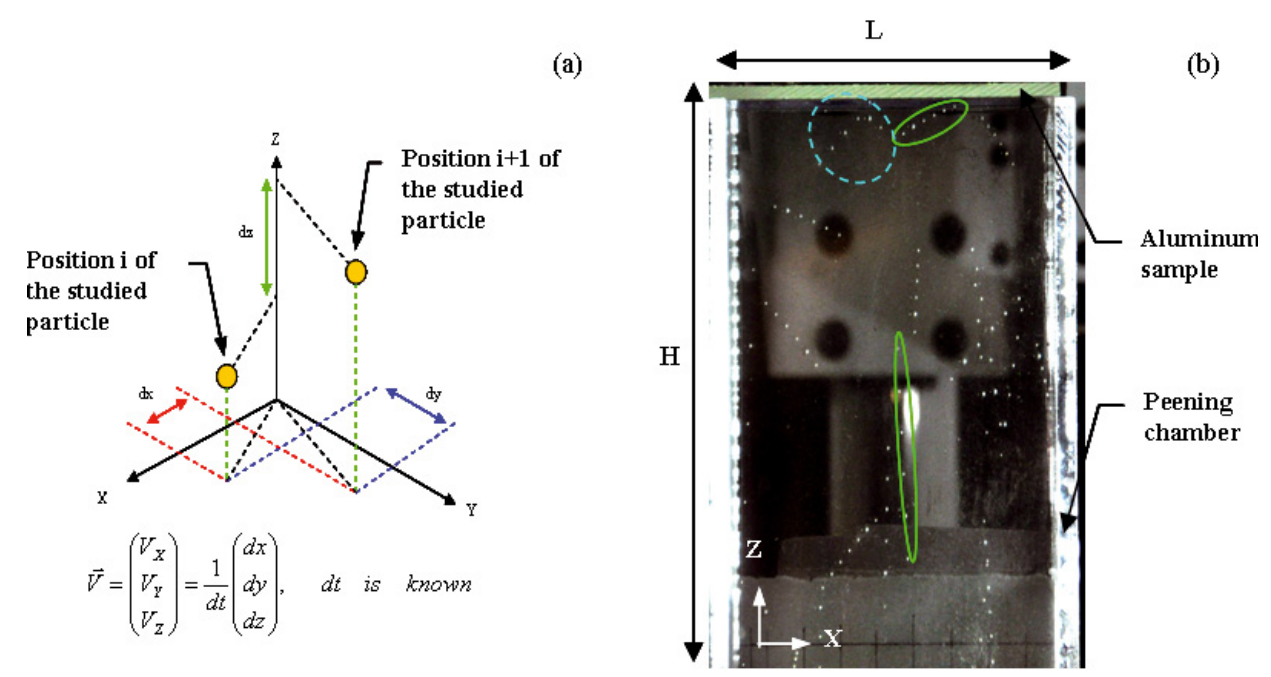

Fig. 6. (a) Measuring a particle velocity using two successive positions. (b) Example of the captured images of shot trajectories, using the optical method. Trajectories of shot in free flight $\circlearrowright$ trajectory of a shot impacting the sample $ニ=)$. 


\begin{tabular}{|l|}
$\mathrm{V}_{\text {moy }} \operatorname{Exp}=1.16 \mathrm{~m} \cdot \mathrm{s}^{-1}$ \\
$\mathrm{~V}_{\text {moy }}^{\text {Num }}=2.40 \mathrm{~m} \cdot \mathrm{s}^{-1}$
\end{tabular}

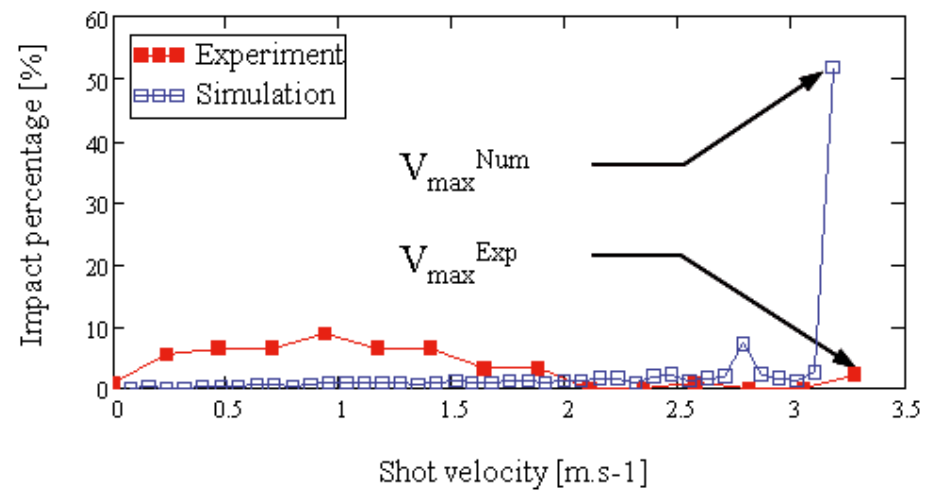

Fig. 7. Normal impact velocity distribution, at the peened sample. $(\square \square \square)$ numerical distribution obtained with 2513 impacts.

In this section, we expose the first preliminary results of the feasibility study conducted for the experimental setup, using at this stage only one camera which gives access to shot trajectories in the $(X, Z)$ plan, as shown in Figure 6b. Only the $Z$ component of the shot velocity will be studied in Section 3.1. To do so, a plexiglas parallelepipedic chamber $(L=85 \mathrm{~mm}, B=36 \mathrm{~mm}$ and $H=360 \mathrm{~mm}$ ) is used, in which are placed 50 particles of $2 \mathrm{~mm}$ in diameter made of $100 \mathrm{Cr} 6$ steel.

In Figure 6b, different trajectories can be seen, thus providing information about physical parameters such as impact velocities and angles in the $(X, Z)$ plan, as well as numerical parameters like the restitution coefficients for the different walls (sonotrode, chamber and sample). In parallel, the model was used to reproduce numerically the experimental conditions of this study. The first preliminary results of this simulation-experiment comparison are presented below.

\subsection{Shot velocity}

The multitude of photographs taken gives direct access to the normal component of the shot velocities $V_{z}$, from which can be calculated the normal impact velocity distribution at the peened sample. The velocity distribution is the percentage of impacts for velocity intervals defined from 0 to $V_{\max }$, the maximum recorded normal velocity.

In Figure 7, we notice differences between the numerical and experimental results. Experimentally, the distribution is maximal for a normal impact velocity of $0.9 \mathrm{~m} \cdot \mathrm{s}^{-1}$, whereas numerically it is maximal for $V_{\max }^{\text {Num }}=$ $3.2 \mathrm{~m} . \mathrm{s}^{-1}$. It is important to precise that the numerical results are based on 2513 impacts, contrarily to experimental results that rely on only 46 shot trajectories, extracted from a dozen photographs, and resulting in a very poor statistics. However, we notice that both of the numerical and experimental normal velocity ranges are very similar. In fact, $V_{\max }^{\operatorname{Exp}}$ and $V_{\max }^{\mathrm{Num}}$ equal respectively to 3.28 and $3.18 \mathrm{~m} \cdot \mathrm{s}^{-1}$.
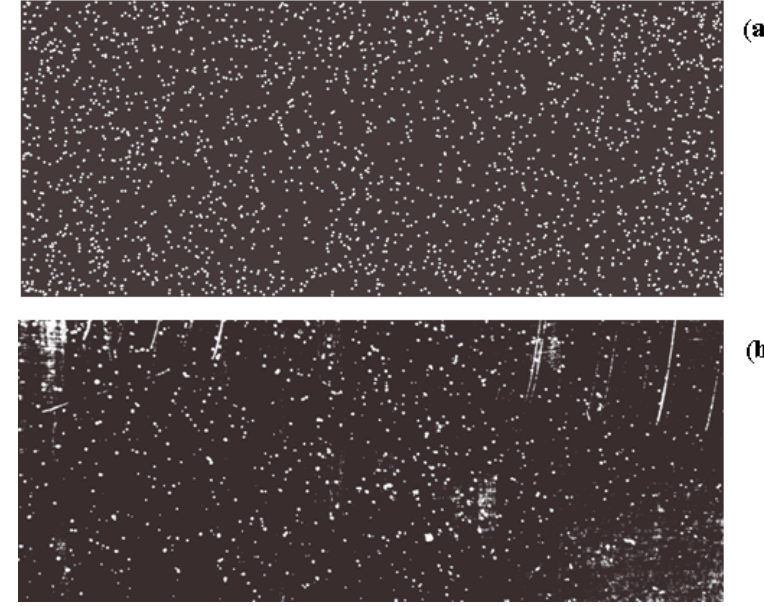

(b)

Fig. 8. Impact distribution on the sample peened surface allows to determine its coverage rate $R$. (a) Numerical coverage rate of the sample $R=7.3 \%$. (b) Experimental coverage rate of the sample $R=4.3 \%$.

\subsection{Coverage rate}

If we look at the coverage rates obtained experimentally and numerically on the sample after a peening time of $30 \mathrm{~s}$, we observe relatively close results.

Figures $8 \mathrm{a}$ and $8 \mathrm{~b}$ correspond respectively to the coverage of the sample, obtained numerically and experimentally. We observe relatively similar coverage rates between the simulation $(R=7.3 \%)$ and the experiment $(R=4.3 \%)$. Even though it seems that the model slightly over estimates the amount on impacts, it is important to specify that on the experimental sample (Fig. 8b), a fraction of the impacts does not leave visible prints due to their low impact energy.

\section{Conclusion}

Thanks to the model, it is now possible to study in detail the shot dynamics during an ultrasonic peening operation and extract key information about impact velocities and angles, or the coverage of the peened sample. 
Based on the results of Section 2 study, we observed a direct relationship between the system density (the occupied volume by the shot in the chamber) and the different distributions presented. We realize that the dynamics of the shot is complex and depends strongly on the process parameters, but also that the impact velocities and angles distributions are heterogeneous and far from being trivial.

The observed differences could result from several factors like the poor statistics of the preliminary experimental data, or the simplifying assumptions of the actual version of the model (absence of rotational kinetic energy, or considering instantaneous impacts). However, the use of both cameras and piezoelectric sensors, directly placed on the sample, should allow resolving this problem. From an experimental point of view, the developed setup allows real-time access to the physical parameters that characterize ultrasonic shot peening and have a direct influence on the residual stresses distribution generated in the peened material. The first experimental results are information-rich and easily exploitable, making this experimental setup very promising. From a numerical point of view, we see that the model allows obtaining results that are close and from the same magnitude than the ones gathered experimentally.

Acknowledgements. We wish to express our special thanks to SNECMA, in their financial support for this research work, which is part of the MAIA project. We would like also to thank both engineering students, from the University of Technology of Troyes, Miriam Kozemjakin Da Silva and Mengchun Ding for their precious help in the design of the experimental peening chamber.

\section{References}

[1] Y.M. Xing, J. Lu, An experimental study of residual stress induced by ultrasonic shot peening, J. Mater. Process. Technol. 152 (2004) 56-61

[2] B.N. Mordyuk, G.I. Prokopenko, Ultrasonic impact peening for the surface properties' management, J. Sound Vib. 308 (2007) 855-866

[3] B.L. Boyce, X. Chen, J.W. Hutchinson, R.O. Ritchie, The residual stress state due to a spherical hard-body impact, Mech. Mater. 33 (2001) 441-454

[4] H.Y. Miao, S. Larose, C. Perron, M. Lévesque, On the potential applications of a 3D random finite element model for the simulation of shot peening, Adv. Eng. Softw. 40 (2009) 1023-1038
[5] G.H. Majzoobi, R. Azizi, A. Alavi Nia, A threedimensional simulation of shot peening process using multiple shot impacts, J. Mater. Process. Technol. 164-165 (2005) 1226-1234

[6] M. Frija, T. Hassine, R. Fathallah, C. Bouraoui, A. Dogui, Finite element modelling of shot peening process: prediction of the compressive residual stresses, the plastic deformations and the surface integrity, Mater. Sci. Eng. A 426 (2006) 173-180

[7] I. Chaieb, Analyse et simulation des contraintes résiduelles induites par des traitements mécaniques de précontrainte en grenaillage et choc laser, Thèse, Université de Reims Champagne-Ardenne, 2004

[8] A.S. Franchima, V.S. de Campos, D.N. Travessa, C. de Moura Neto, Analytical modelling for residual stresses produced by shot peening, Materials and Design 30 (2009) 1556-1560

[9] C. Ould Mohamed Mahmoud, Analyse des contraintes résiduelles générées lors du grenaillage: approches analytique, numérique et expérimentale des impacts de billes, Thèse, Université de Technologie de Troyes, 2007

[10] Y. Jiyan, W. Xiaoming, L. Yongxin, Velocity and position measurement for projectile using double optical detectors and reflectors, Symposium on Photonics and Optoelectronics, 2009

[11] M. Sommerfeld, N. Huber, Experimental analysis and modelling of particle-wall collisions, Int. J. Multiphase Flow 25 (1999) 1457-1489

[12] A. Hribernik, G. Bombek, Improved method for shot particle velocity measurement within a shotblasting chamber, Flow Meas. Instrum. 17 (2006) 99-105

[13] H. Chardin, Étude de la densification par grenaillage ultrasons d'un matériau métallique poreux élaboré par métallurgie des poudres, Thèse, École Nationale Supérieure des Mines de Paris, 1996

[14] N.V. Brilliantov, F. Spahn, J.M. Hertzsch, T. Pöschel, Model for collisions in granular gases, Phys. Rev. E 53 (1996) 5382

[15] R.M. Brach, Impact dynamics with applications to solid particle erosion, Int. J. Impact Eng. 7 (1998) 37-53

[16] S. McNamara, E. Falcon, Simulations of vibrated granular medium with impact-velocity-dependent restitution coefficient, Phys. Rev. E 71 (2005) 031302

[17] M. Micoulaut, S. Mechkov, D. Retraint, P. Viot, M. François, Granular gases in mechanical engineering: on the origin of heterogeneous ultrasonic shot peening, Granular Matter 9 (2007) 25-33

[18] M. Micoulaut, D. Retraint, P. Viot, M. François, Heterogeneous ultrasonic shot peening: experiment and simulation, ICSP9, Marne la Vallée, France, 2005, pp. $119-124$ 